\title{
Land Surface Temperature Mapping Using Geoinformation Techniques
}

\author{
Chukwuka Friday Agbor* and Esther Oluwafunmilayo Makinde \\ Laboratory for Geospatial Research, Department of Surveying and Geoinformatics, Faculty \\ of Engineering, University of Lagos, Akoka Lagos State, Nigeria \\ *Corresponding author: chukwuka_friday@yahoo.com
}

\begin{abstract}
General environmental management, which involves monitoring and modeling, requires the information of the Land surface temperature (LST) status of area concerned. Land surface temperature has gained relevance recognition over the years and there is need to develop approaches that can determine LST using satellite images. This study was conducted in Akure which has experienced rapid urbanization in recent time. The study utilized Landsat data of 1984, 1990, 2000, 2003, 2014 and 2016. The temperature data were derived from Landsat images using remote sensing algorithms for assessing LST from thermal infrared (TIR) data (bands 6 and 10). These data were processed and analyzed using tools in Idrisi and ArcGIS software systems. Surface temperatures derived from Landsat data were validated with ground meteorological data. The results revealed parabolic increase in temperature over the years and the changing pattern was investigated by adopting existing bio-spectral phenomenon Models. The validation operation revealed average bias value of \pm 0.31 between remote sensing- and ground-based data. This implies that remote sensing technique is reliable and therefore could be employed for large scale temperature mapping. The results could be used in mitigating urban heat island effects such as heat-related stress and ill-timed human deaths.
\end{abstract}

Keywords: Land surface temperature; environmental monitoring; terrain emissivity; urban heat island.

\section{Introduction}

Akure has experienced rapid development and high growth of urbanization in the past few decades. These environmental transformations have changed the physical and natural environment of the area. Urban encroachment has been obvious on the suburbs and this has transformed rural environment into a new urban landscape. Akure urban growth rate is quite very fast with very high population growth rate (Aderoju et al, 2013). According to (Balogun et al, 2015), built up environment of Akure has increased significantly by $20 \%$ between 2002 and 2006. The biodiversity, ecosystem functions, local and regional climate and the quality of life, have been affected by the growth of urban areas (Luck et al, 2002). The land surface transformation in the city and the disappearance of vegetation cover by paved surfaces are some of the causes of urban heat island (UHI) development (Voogt, 1984). Urban heat island is a major outcome of urban expansion that leads to temperature increase in the city in comparison to suburbs (Liu et al. 2011). Urban heat island (UHI) has long been a concern for more than four decades (Liqin et al, 2008).

Urban Heat Island was first introduced by Howard in 1833, and till now this environmental phenomenon has gained much attention (Laosuwan et al, 2012). An urban heat island is the term used to describe the distinctive warmth of both the surfaces and atmosphere in cities compared to their surroundings (James, 2004). The heat island is an example of unpremedi- 
tated climate alteration when urbanization changes the characteristics of the Earth's surface and atmosphere (James, 2004). According to 'The Heat Island Group' the chief causes of urban heat islands are the presence of dark surfaces and the nonexistence of vegetation cover (The Heat Island Group, 2005).

This study was set to estimate land surface temperature (LST) using remote sensing technique and examine the dynamics in temperature using environmental indexes. This was accomplished by surface temperature data retrieval from thermal infrared (TIR) and Red bands of Landsat images. Retrieved land surface temperature from Landsat images was validated with ground meteorological data.

\section{Data and Methods}

\subsection{Study area and data}

\section{Location}

This study was carried out in Akure and its suburbs with Akure as the major dominating town. It lies between longitude $5^{\circ} 06^{\prime} \mathrm{E}$ to $5^{\circ} 38^{\prime} \mathrm{E}$ and between latitude $7^{\circ} 07^{\prime} \mathrm{N}$ to $7^{\circ} 37^{\prime} \mathrm{N}$ in South-west Nigeria. The three major settlements within the area include Apomu, Ipogun, and Akure. The area covers about 161989.2 hectares.

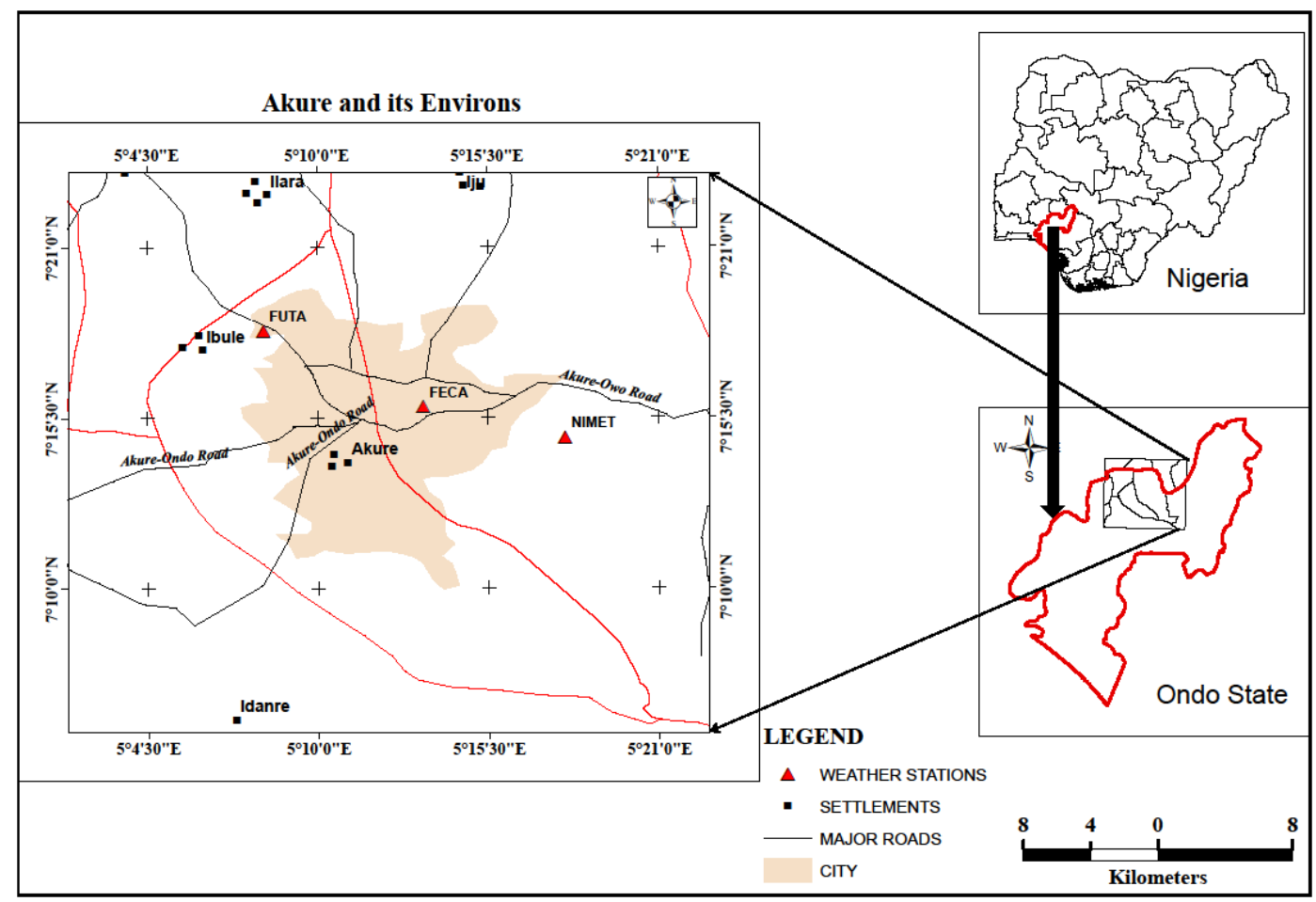

Figure 1: The study area.

The area experiences warm humid tropical climate, with average rainfall of about $1420 \mathrm{~mm}$ per annum with the little short break in August. The rainfall distribution is seasonal with a short dry season occurring usually between December and March. The area is characterized 
by a principal rainy season occurring in May, June and first half of July, and a secondary rainy season in the latter half of September and October. The Annual average temperature of the area is $31.3^{\circ} \mathrm{C}$ and its mean annual relative humidity is about $82 \%$ (data based on 2014 data from the Nigerian Meteorological Agency). The area is characterized by rain forest. The rainfall and temperature distribution is represented in Figure 2.

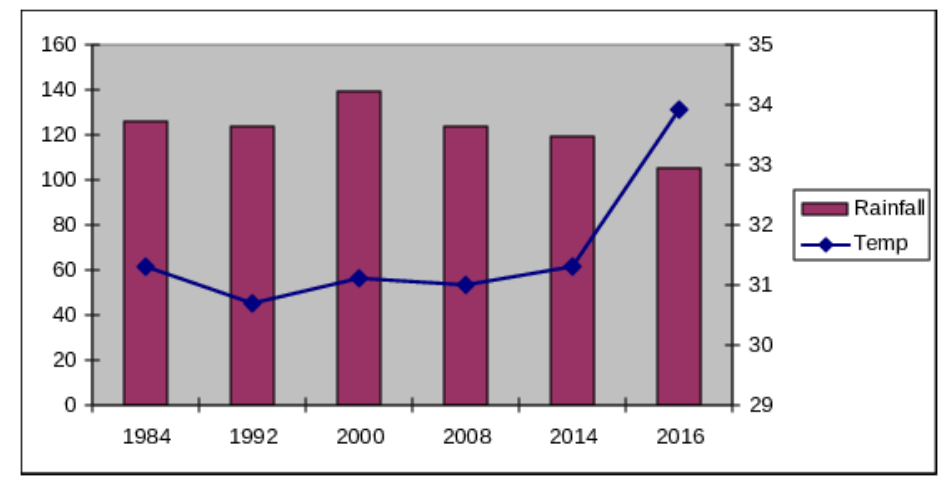

Figure 2: Rainfall and Temperature distribution between 1984 and 2016.

The city was occupied by a population said to be below 50,000 in 1952 and 70,641 in 1963 . It increased to around 110,000 in 1980, and rose to 484,798 in 2006 (National Bureau of Statistics, 2010). The area is characterized by dense settlement pattern.

To determine land surface temperature and surface emissivity, Landsat satellite images of 1984, 1992, 2000, 2003, 2014 and 2016 were downloaded from the official website of US Geological Survey (USGS). The study area is located in the Landsat path/row of 190/55 (table 1). The study did not utilize TIRS Band 11 of OLI in estimating brightness temperature due to its larger calibration uncertainty, following January 6, 2014, recommendations of USGS (Ugur et al, 2016). Both satellite and field data were used to analyze LST variation and emissivity characteristics within the study area.

Table 1: Satellite Images

\begin{tabular}{llcccc}
\hline Satellite Sensor & Spatial resolution & Acquisition years & Path & Row & Source \\
\hline Landsat 5,7 & $30 \mathrm{~m} \times 30 \mathrm{~m}$ & $1984,1992,2000$, and 2003 & 190 & 55 & GLCF \\
Landsat 8 & $30 \mathrm{~m} \times 30 \mathrm{~m}$ & 2014 and 2016 & & & GLOVIS \\
\hline
\end{tabular}

\subsection{Retrieval of LST from the Landsat TIR images}

The LST was retrieved using two major steps: First, the conversion of digital numbers (DNs) of band6 to Atmospheric radiance $\left(A_{r}\right)$ using equation 1 (Giannini et al, 2015).

$$
A_{r}=\left(\frac{L_{\max } \lambda-L_{\min } \lambda}{Q_{\text {cal }} \lambda}\right) Q_{\mathrm{cal}}+L_{\min } \lambda
$$

where $A_{r}$ is the radiance at the sensor [W/( $\left.\left.\mathrm{m}^{2} \mathrm{sr} \mu \mathrm{m}\right)\right], Q_{\text {cal }}$ is the image value $(\mathrm{DN}), Q_{\text {cal }}$ min represents the minimum $\mathrm{DN}$ value corresponding to $L_{\min } \lambda, Q_{\mathrm{cal}} \max$ is the Maximum pixel value corresponding to $L_{\max } \lambda, L_{\min } \lambda$ is at-sensor radiance scaled to $Q_{\text {cal }} \min$ in $\left[\mathrm{W} /\left(\mathrm{m}^{2} \mathrm{sr}\right.\right.$ $\mu \mathrm{m})]$, 

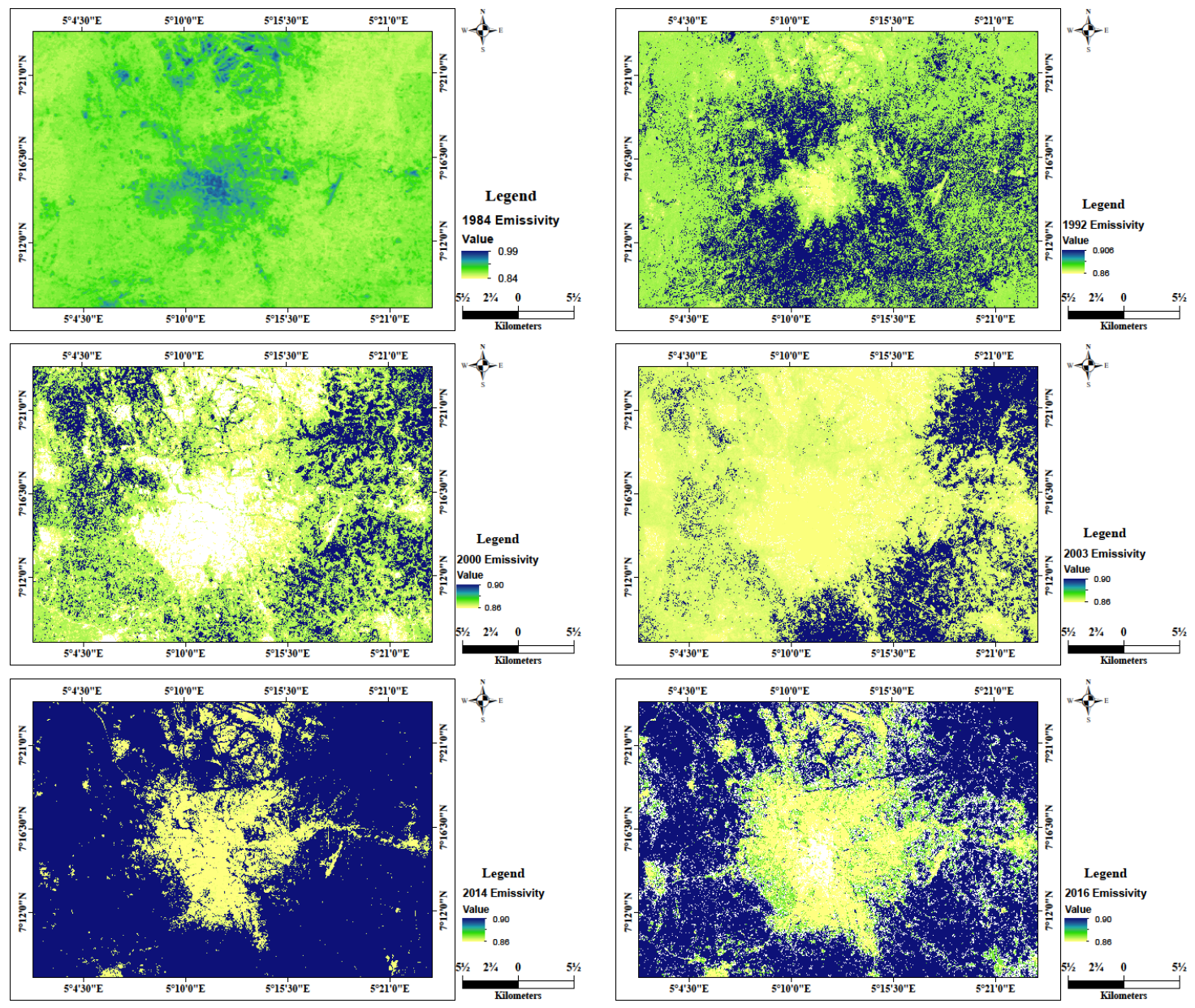

Figure 3: Surface emissivity maps.

$L_{\max } \lambda$ is at-sensor radiance scaled to $Q_{\mathrm{cal}} \max$ in $\left[\mathrm{W} /\left(\mathrm{m}^{2} \mathrm{sr} \mu \mathrm{m}\right)\right]$. was calculated by the equation 2 in the case of Landsat 7:

$$
A_{r}=\left(\frac{L_{\max }-L_{\min }}{Q_{\text {cal }} \max -Q_{\text {cal }} \min }\right) *\left(Q_{\text {cal }}-Q_{\text {cal }} \min \right)+L_{\text {min }}
$$

where $Q_{\text {cal }} \min =1, Q_{\text {cal }} \min =255, Q_{\text {cal }}=D N$ and $L_{\max }$ and $L_{\min }$ are given in the metadata.

To retrieve $A_{r}$ from Landsat 8 image, the Ugur et al, 2016 formula (equation 3) was adopted:

$$
A_{r}=m x+a
$$

where $m$ is the multiplicative rescaling factor, $x$ stands for the Band 10, and $a$ is the additive rescaling factor.

The next step was to convert the surface radiance to brightness temperature $\left(B_{t}\right)$ using the thermal constants provided in the metadata. Equation 4 was used:

$$
B_{t}=\left(\frac{K_{2}}{\ln \left(\frac{k_{1}}{A_{r}}+1\right)}\right)-273.15
$$



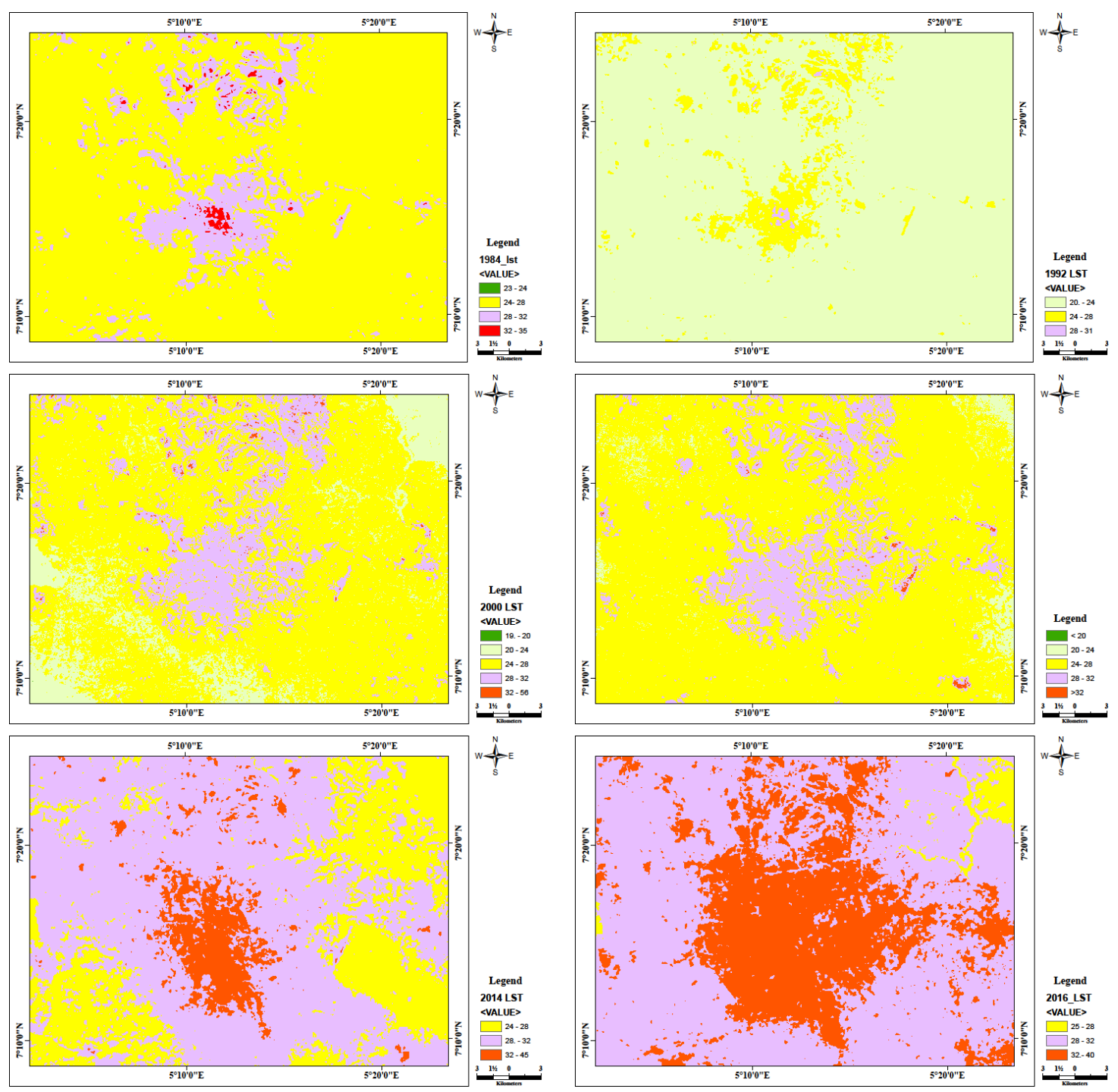

Figure 4: Changing pattern of heat zones in Akure and its environs over the years.

where $B_{t}={ }^{\circ}$ Kelvin, $A_{r}=$ Top of Atmosphere radiance, $K_{1}$ and $K_{2}=$ thermal conversion constants from the metadata.

LST was derived from TM6 and OLI 10 using emissivity corrected model (equation 5):

$$
S_{t}=\frac{T}{1+\left(\frac{\lambda \times T}{A_{r}+1}\right) \ln \varepsilon}
$$

where $S_{t}=\mathrm{LST}, \lambda=$ wavelength of emitted radiance $(11.345$ for TM/ETM and $11.5 \mu \mathrm{m}$ for OLI $), \rho=\mathrm{h} \times \mathrm{c} /\left(1.438 \times 10^{-2} \mathrm{~m} \mathrm{~K}\right), \sigma=$ Boltzman constant $\left(1.38 \times 10^{-23} \mathrm{~J} / \mathrm{K}\right), \mathrm{h}=$ Planck's constant $\left(6.626 \times 10^{-34} \mathrm{~J} \mathrm{~s}\right), c=$ velocity of light $(2.998 \times 108 \mathrm{~m} / \mathrm{s}), \varepsilon=$ denotes emissivity (Lillesand et al, 2008). 


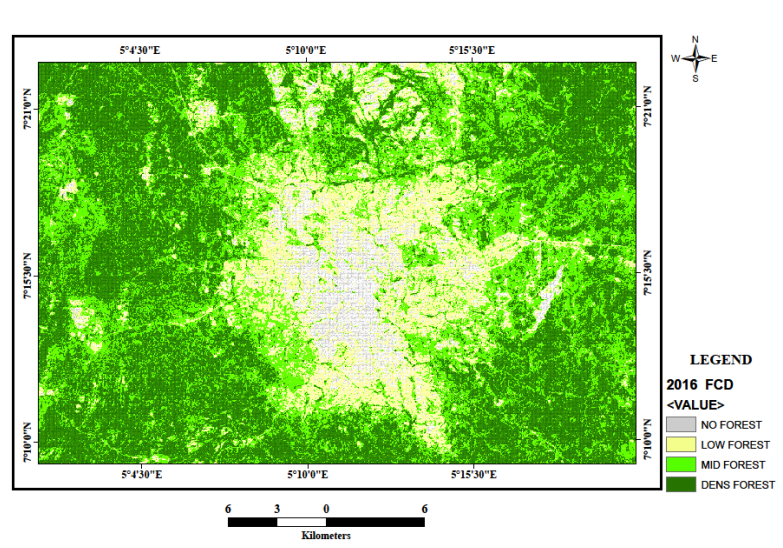

(a)

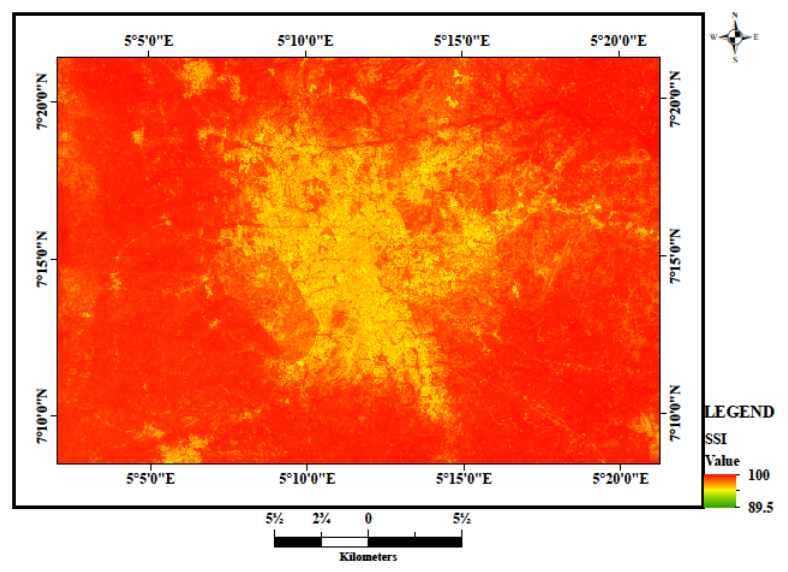

(c)

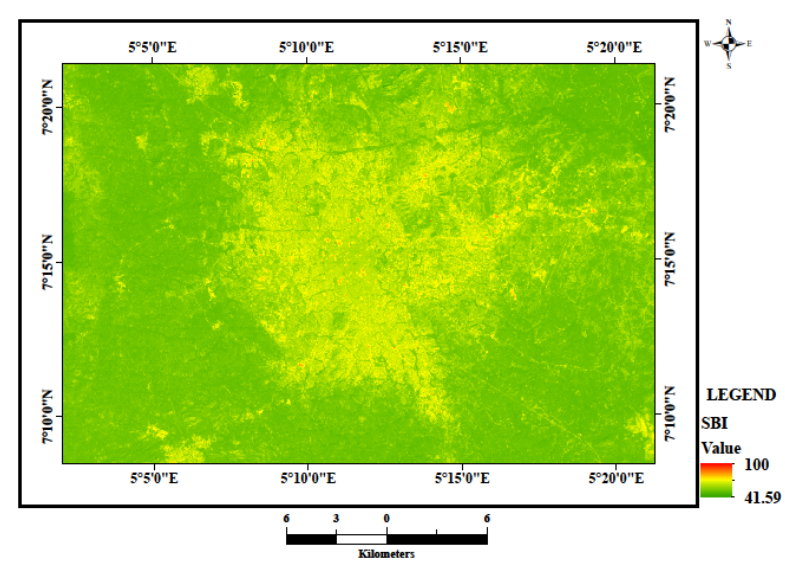

(b)

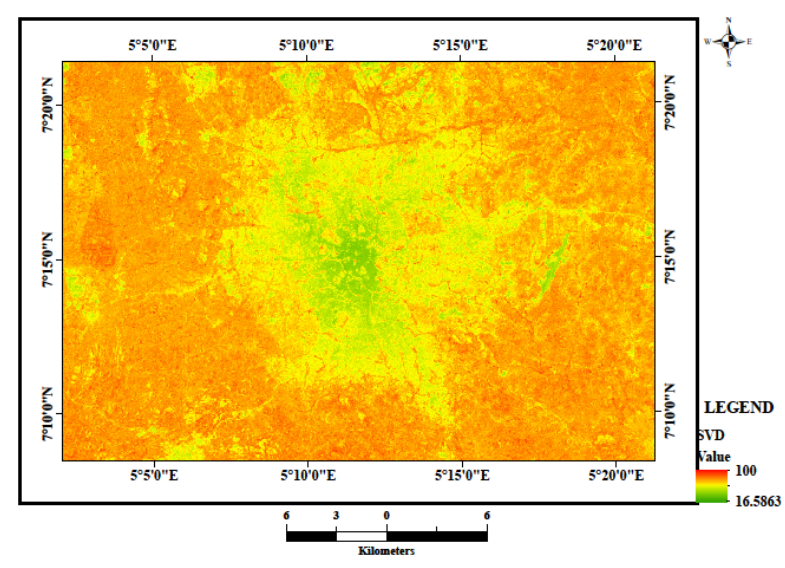

(d)

Figure 5: 2016 FCD (a), SBI (b), SSI (c) and SVD (d) maps.

\section{Land surface temperature emissivity estimation}

Land surface emissivity $(\varepsilon)$ is a proportionally factor that scales blackbody radiance (Planck's law) to predict emitted radiance, (Lillesand et al, 2008). It is the efficiency of transmitting thermal energy across the surface into the atmosphere. In this sense, emissivity $\varepsilon$ must be known in order to estimate LST accurately from radiance measurements. Knowledge of the emissivity spectrum is also useful for terrestrial and planetary geological studies to map surface materials based on differences in wavelength-dependent spectral features. (Lillesand et al, 2008).

A number of methods have been explored to estimate surface emissivity (Jose et al, 2008): Alpha-Derived Emissivity (ADE), Emissivity Bounds method (EBM), Gray body Emissivity method (GEM), Normalized Emissivity method (NEM) etc. Some of these methods have limitations e.g. ADE, NEM and TISI (temperature-independent spectral indices) only provide relative emissivity values, while some require a prior knowledge of the emissivity values to be assigned to each class; the assumption involved in GEM of gray body behaviour is not usually accomplished (Jose et al, 2008). 
The limitations of the different existing methods has led the development of methods based on normalized difference vegetation index (NDVI) estimations from visible and near-infrared (VNIR) data for application to sensors without multispectral TIR capabilities. Example of such method is the NDVI thresholds method (NDVI-THM) (Sobrino et al, 2002) employed in this study.

\section{NDVI-THM}

Different methods have been used to predict LSE from NDVI values (Valor et al, 1996). NDVI-THM uses certain NDVI values (thresholds to distinguish between soil pixels (NDVI $<$ NDVIs) and pixels of full vegetation (NDVI > NDVIv). For those pixels composed of soil and vegetation (mixed pixels, NDVIs $\leq$ NDVIv), the method uses the following simplified equation (Sobrino et al, 2002).:

$$
\varepsilon=\varepsilon_{s} \lambda+\left(\varepsilon_{v} \lambda-\varepsilon_{s} \lambda\right) P_{v}
$$

where, $\varepsilon_{v}$ and $\varepsilon_{s}$ are respectively, the soil and vegetation emissivity, $P_{v}$ is the proportion of vegetation (also referred to as fraction vegetation cover, $F V C$ ). Note that equation (6) is only valid for a mixed area (mixed pixels).Spectral reflectance values were converted to emissivity using kirchoff's law (equation 8). Equation 8 explains the direct relationship between an objects emissivity and its reflectance.

$$
\varepsilon(\lambda)+\rho(\lambda)=1
$$

$P_{v}$ values were obtained from the NDVI according to Carlson and Ripley, 1997:

$$
P_{V}=\left(\frac{N D V I-N D V I_{\min }}{N D V I_{\max }-N D V I_{\min }}\right)^{2}
$$

With values of $N D V I_{V}=0.5$ and $N D V I_{S}=0.2$ proposed in Sobrino et al, 2002, to apply the method in global conditions. The forest cover index (FCD) of the study area shows $N D V I_{V}=0.40$ and $N D V I_{S}=0.20$ and adopted for $P_{V}$ estimation.

The purpose of this is to correct the effect of emissivity on radiating energy in areas of mixed pixels. The resulting surface emissivity threshold was used to produce emissivity images for the land surface temperature correction.

\subsection{Ground Temperature Data Measurements}

\section{Instrumentation and Meteorological Observations}

The ground temperature data were collected from three stations located randomly within the study area. The purpose of this exercise is to make a direct comparison of satellite-derived LST with collocated temperature from ground-based instruments possible (Schneider et al., 2012). The In-situ measurements were carried out at NIMET, FECA and FUTA on the $2^{\text {nd }}$ of January, 2016. 


\section{Site Selection}

The ground sites exhibit homogeneous surface properties on a scale of at least $3 \times 3$ pixels. (Schneider et al, 2012). This criterion was observed before choosing the ground stations. The average height of the platforms is $2 \mathrm{~m}$. Norman et al, (1995) used a range of $1 \mathrm{~m}$ to $2 \mathrm{~m}$. The choice of the monitoring sites was influenced by the distribution of available meteorological stations.

\section{Validation of Derived Land Surface Temperature (LST)}

\subsection{Through Near-Surface Air Temperature}

The validation of derived surface temperature involved the use of mean air-temperatures (Table 2) from three ground stations within the study area and the actual air-temperature of the collocated pixels on the same day of the satellite passing for three locations (Liu et al, 2011).

\subsection{Reporting of Validation Results}

The results of LST validation has been reported in quantitative form by computing the bias or deviation (Table 6) as (Schneider et al, 2012):

$$
\text { Bias }=L S T_{\mathrm{s} a t}-L S T_{\mathrm{ref}}
$$

where $L S T_{\text {sat- }}$ satellite-derived LST and $L S T_{\text {ref- }}$ observation of a given reference LST, which is assumed to be closer to the true value (Schneider et al, 2012).

This convention ensures that a positive bias is indicative of an overestimate of the satellite LST, whereas a negative bias reflects a satellite LST that is too low with respect to the reference data set. (Schneider et al, 2012).

\subsection{Historic investigation of surface temperature characteristics}

The temporal characteristics of temperature were examined by linking land surface temperature (LST) with ecological indexes (Weng, 2001).This objectives was achieved by adopting two different ecological models. These include Aridity Index model (Kirtti et al, 2012) and Bio-Spectral Phenomenon Modeling (Slady et al, 2016).

\section{Aridity Index}

The aridity index explains temperature characteristics due to degree of dryness of various years within the study area. Angström (1936) in Kirtti et al, 2012, suggested an index of aridity. He discovered that the aridity index was proportional to length of precipitation. His humidity coefficient adopted in this research is written as:

$$
I_{A}=\frac{P}{1.07^{T}}
$$

In general, the aridity index formula shows that when rainfall/precipitation is higher and temperature lower, there will be high aridity index and subsequently, high moisture. On 
a comparative scale, the condition is said to be drought if the index value lies below 20 $\left(I_{A}<20\right)$, and if it is less than $10(l<10)$, then it is desert-like situation. Values above 20 depict wetland (Kirtti et al, 2012).

\section{The Bio-Spectral Phenomenon Models and Temperature}

This is often used to investigate the relationship between temperature and other ecological factors like forest canopy density, forest shadow and soil (Slady et al, 2016). Forest Canopy Density model utilizes forest canopy density as an essential parameter for characterizing of forest conditions (Slady et al, 2016). This model involves bio-spectral phenomenon modeling and analysis utilizing data derived from four indexes (Slady et al, 2016): the Advance Vegetation Index (AVI), Bare Soil Index (BI), Shadow Index or Scaled Shadow Index (SI, SSI) and the Thermal Index (TI).

i. Advanced vegetation index

NDVI lacks the ability to identify subtle differences in canopy density (James, 2005). The advanced vegetation index (AVI) was used in this study instead. It has been more sensitive to forest density and physiognomic vegetation classes than NDVI (Slady et al, 2016). AVI was calculated using equation 11.

$$
A V I=\left\{\left(B_{6}+1\right)\left(65536-B_{4}\right)\left(B_{5}-B_{4}\right)\right\}^{1 / 3}
$$

\section{ii. Bare Soil Index}

Similar to the AVI, the bare soil index (BI) is a normalized index calculated using equations 12 (Azizi et al, 2008).

$$
B I=\left\{\frac{\left(B_{6}+B_{4}\right)-\left(B_{5}+B_{2}\right)}{\left(B_{6}+B_{4}\right)+\left(B_{5}+B_{2}\right)}\right\} * 100+100
$$

iii. Canopy shadow Index

The arrangement of the forest crown causes shadow which affects the spectral responses. Young forest trees have low canopy shadow index (SI) compared to mature natural forest. The mature forest shows low spectral axis in comparison to that of the open area. SI was calculated using equation 13 (Azizi et al, 2008).

$$
S I=\left\{\left(65536-B_{2}\right)\left(65536-B_{3}\right)\left(65536-B_{6}\right)\right\}^{1 / 3}
$$

iv. Thermal Index (TI)

Two factors cause the relatively cool temperature due to availability of forest. One is the shielding effect of the forest canopy, which wedges and absorbs energy from the natural energy source (the sun). The second factor is the evaporation from the leaf surface, which reduces warming. This forms the basis for the thermal index (Azizi et al, 2008). The thermal information in this study was derived from the thermal infrared band of Landsat images (see section 2.2). 
v. Forest Canopy Index (FCD)

Using the three indexes, the canopy density was calculated in percentage for each pixel. Vegetation Index was obtained through Principal Component Analysis between AVI and BI and then scaled from 0 to 100 to form Scaled Vegetation Index (SVD). Scaled shadow index (SSI) was calculated using a linear transformation function from normalized SI. Maximum SSI (100\%) represents the highest possible shadow while minimum represents the opposite.

$$
F C D=\sqrt{(S V D * S S I+1)}-1
$$

All data extraction through the existing respective equations was computed in Idrisi Selva software. All of the above equations were completed using the image Calculator to compute respective values.. Fuzzy Membership transforms the input raster into a 0 - 1 scale indicating the strength of a membership in a set, based on a specified fuzzy algorithm. Linear membership option calculates membership based on the linear transformation of the input raster and assigns a membership value of 0 at the minimum and a membership of 1 at the maximum.

The degree of forest density is expressed in percentages: $10 \%$ FCD, $20 \%, 30 \%, 40 \%$ and so on. The Figures 3 and 4 (pages 20 and 21) indicate forest canopy density map of the study area for 2000 and 2016.

\section{Result and discussion}

\subsection{Land surface temperature distribution within the area}

Table 2 provides a summary of at-sensor brightness temperature for the Thematic Mapper (TM), Enhanced Thematic Mapper (ETM/ETM+), and Operational Land Imager (OLI) sensors.

Table 2: The ranges of temperatures at-satellite over the years.

\begin{tabular}{ccccc}
\hline Dates & $\begin{array}{c}K_{1} \\
{\left[\mathrm{~W} /\left(\mathrm{m}^{2} \mathrm{sr} \mu \mathrm{m}\right)\right]}\end{array}$ & $\begin{array}{c}K_{2} \\
(\text { Kelvin })\end{array}$ & TOA & $T_{\mathrm{S} A T}\left({ }^{\circ} \mathrm{C}\right)$ \\
\hline 1984 & 607.76 & 1260.66 & $8.81-10.3$ & $23.61-34.73$ \\
1992 & 671.62 & 1284.30 & $8.55-9.98$ & $20.33-30.98$ \\
2000 & 666.09 & 1282.71 & $8.37-13.87$ & $19.13-56.39$ \\
2003 & 666.09 & 1282.71 & $8.37-10.52$ & $19.13-34.90$ \\
2014 & 774.8853 & 1321.0789 & $9.23-12.45$ & $24.22-45.41$ \\
2016 & 774.8853 & 1321.0789 & $9.44-11.63$ & $25.71-40.32$ \\
\hline
\end{tabular}

From the table 2 it is obvious that apart from 2014 and 2016, the year 1984 had the highest least temperature value. This is the reason for historical investigation of surface temperature between 1984 and 2016 (figure 7).

\subsection{Land Surface temperature Emissivity correction}

The average land surface emissivity (LSE) was developed using simplified NDVI threshold method and the result is presented in table 3 . 
Table 3: Emissivity Threshold for the study years.

\begin{tabular}{ccc}
\hline$P_{V}$ & LULC & Emissivity \\
\hline$P_{V} \geq 0.40$ & veg & 0.906 \\
$0.2<P_{V} \leq 0.3$ & mixed pixels & $0.86+0.04 P_{V}$ \\
$0.04<P_{V} \leq 0.2$ & soil & 0.861 \\
\hline
\end{tabular}

The values in table 3 were used to simulate proportional vegetation cover images. The threshold was developed using image spectral values and in-situ spectrometer measurements. A total of 18 sites were randomly selected for these measurements (Figure 6). It is also important to state that minimum of five observations were made at each location, which were averaged to give the spectral value of each locations

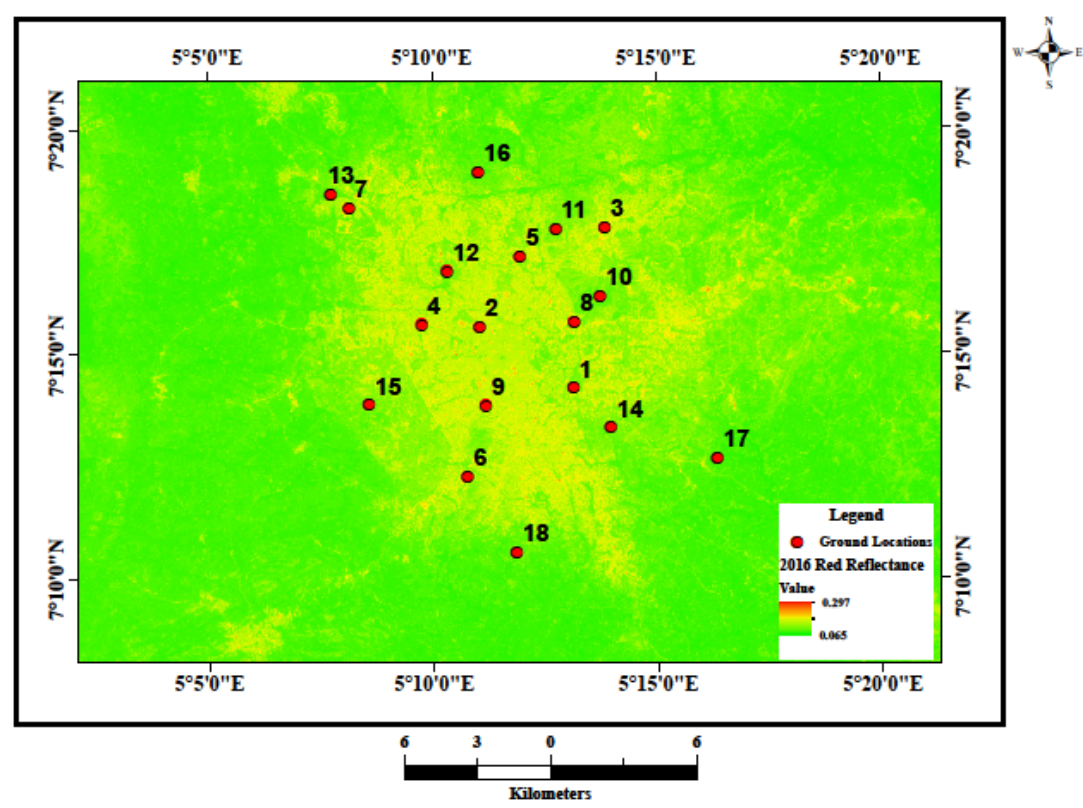

Figure 6: In-situ locations up scaled on OLI reflectance image.

The purpose of this table is to compare field and satellite-based reflectance values as a way of evaluating result from imagery. 2016 Landsat image is the most recent and was therefore chosen for the evaluation. The mean reflectance values were determined between $0.630 \mu \mathrm{m}-$ $0.680 \mathrm{\mu m}$ of the electromagnetic spectrum, which correspond to the red band of OLI Landsat image selected for emissivity estimation (Figure 6). 6.0 version of ViewSpec Pro software was used to extract reflectance values from the spectral profile.

Results show good fits between reflectance values from satellite data and that from in-situ measurements ( $87.1 \%$ for vegetation and $87.4 \%$ for bare soil surfaces). The resulted average emissivity was used to develop the emissivity threshold for this study and is presented in table 3. The simulated images in Figure 3 served as inputs for the LST emissivity $(\varepsilon)$ corrections. The simulation was carried out with spatial analyst tool in ArcGIS 10.1 software.

The emissivity-corrected surface temperature images are those in Figure 4. The images describe the temperature zones of the study area for the years considered. It is obvious that 
in 1984, 2014 and 2016 much part of the area within the city experienced temperature above $32^{\circ} \mathrm{C}$. Though in 2000 and 2003 there were evidence of very high temperature, these were in parches and not as obvious as that of other years.

\subsection{Historic Temperature characteristics}

\section{Characteristics by Aridity Index}

The results of this section revealed historic temperature characteristics due to degree of dryness within the study area. For example, table 4 and Figure 7 show that the dryness in 1984 was higher than that of 1992 and 2000, thus, higher temperature.

Table 4: Mean Surface Temperature and Aridity Index.

\begin{tabular}{lcccccc}
\hline Weather parameters & $\begin{array}{c}1984 \\
\text { Mean } \\
\text { LST }\left({ }^{\circ} \mathrm{C}\right)\end{array}$ & $\begin{array}{c}1992 \\
\text { Mean } \\
\text { LST }\left({ }^{\circ} \mathrm{C}\right)\end{array}$ & $\begin{array}{c}2000 \\
\text { Mean } \\
\text { LST }\left({ }^{\circ} \mathrm{C}\right)\end{array}$ & $\begin{array}{c}2014 \\
\text { Mean LST } \\
\left({ }^{\circ} \mathrm{C}\right)\end{array}$ & $\begin{array}{c}2016 \\
\text { Mean LST } \\
\left({ }^{\circ} \mathrm{C}\right)\end{array}$ & $\begin{array}{c}\text { Mean LST } \\
\left({ }^{\circ} \mathrm{C}\right)\end{array}$ \\
\hline Temperature (derived) & 30.5 & 30.1 & 29.5 & 31.9 & 32.5 & 33.31 \\
Temperature (ground) & 31.8 & 30.73 & 31.11 & 31.3 & - & - \\
Rainfall & 125.62 & 123.58 & 127.73 & 119.01 & - & - \\
Index for temp. derived & 15.95 & 16.12 & 17.36 & 13.75 & & \\
Index for ground temp. & 14.61 & 15.45 & 15.57 & 14.31 & & \\
\hline
\end{tabular}

The humidity index graph below reveals that 1984 experienced the lowest aridity index. This explains the reason for higher temperature in 1984. The year 2000 was characterized by high index, thus, general low temperature.

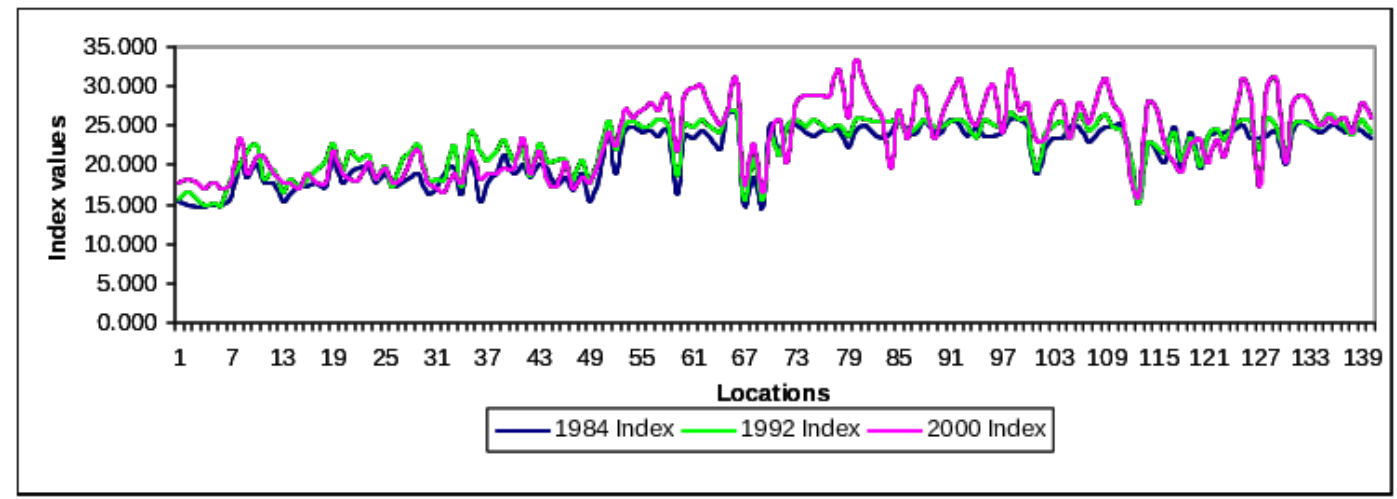

Figure 7: The humidity index.

\section{Characteristics by Forest Cover Indexes}

The output images of these ecological indexes for 2016 (Figure 5) and the graph (Figure 8) further revealed the relationship between temperature and other ecological factors like bare surface indexes (b), forest shadow index (c) and advance vegetation index (d). The values of these indexes were extracted in ArcGIS 10.1 to create the graphs below (Figures 8 and 9 ), which reveal temperature's behaviour in relation to above indexes. The SVD Vegetation 
Index map was obtained through Principal Component Analysis in Idrisi software environment, between AVI and BI and then scaled from 0 to 100 to form Scaled Vegetation Index (SVD). Scaled shadow index (SSI) was calculated using a linear transformation function from normalized SI. Maximum SSI (100\%) represents the highest possible shadow while minimum represents the opposite. The scaling became necessary for easy comparison of the different indexes (Rikimaru et al, 1997)

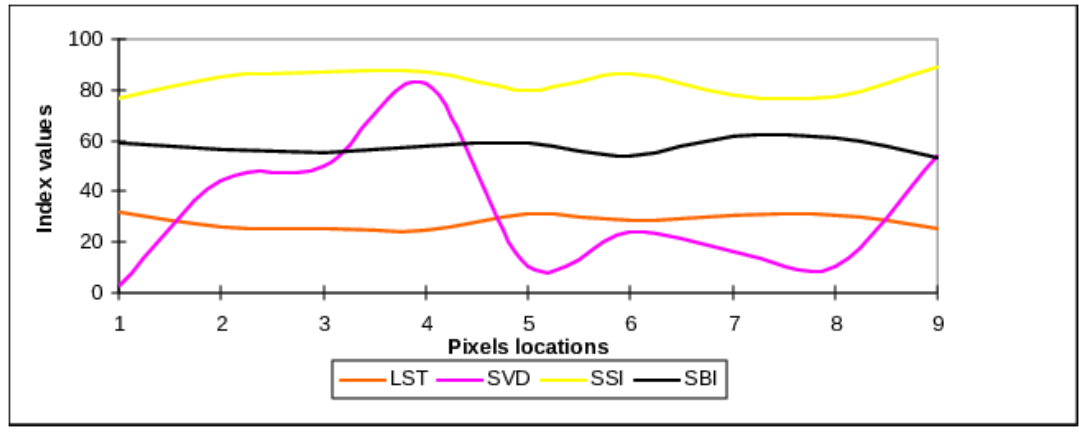

Figure 8: The Characteristics of the three indices and temperature in 2016.

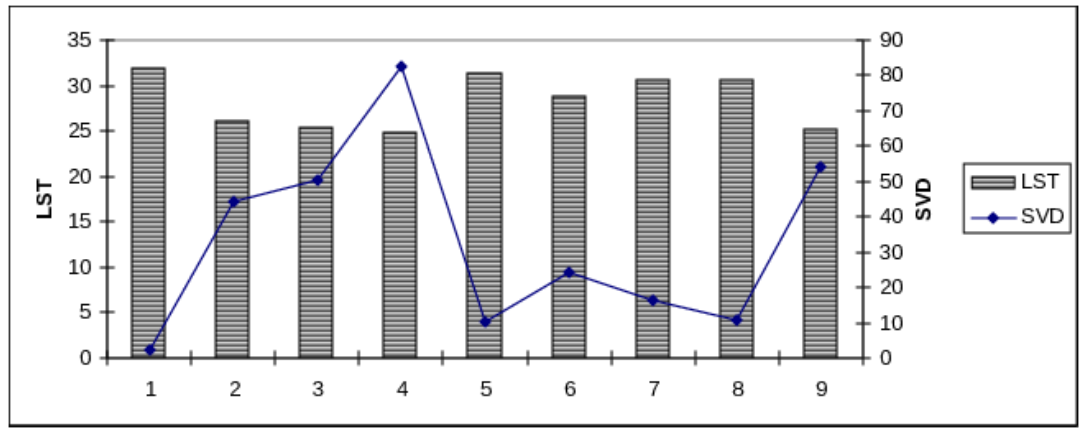

Figure 9: The Characteristics of the vegetation and temperature in 2016.

The Forest Canopy Density Model combines data from the four (4) indices. Figure 8 illustrates the behahiour between forest conditions and LST. It is obvious that as the SVD value increases (vegetation cover) there is a corresponding increase in the SI value (forest shadow). Concurrently, for less bare soil (i.e. a lower BI value) there is a corresponding decrease in the LST value. Bare soil index increases as the bare soil exposure degrees of ground increase. The SI values are primarily dependent on the amount of tall vegetation such as trees, which cast a significant shadow. Shadow index increases as the forest density increases (Figure 8). The strong relationships between surface temperature and bio-spectral indexes such as shadow and bare soil are explained by Figure 9. Upper figure 9 shows temperature increases with increase in bare soil exposure, while lower figure shows that a slight decrease in tree shadow can lead to high temperature. 

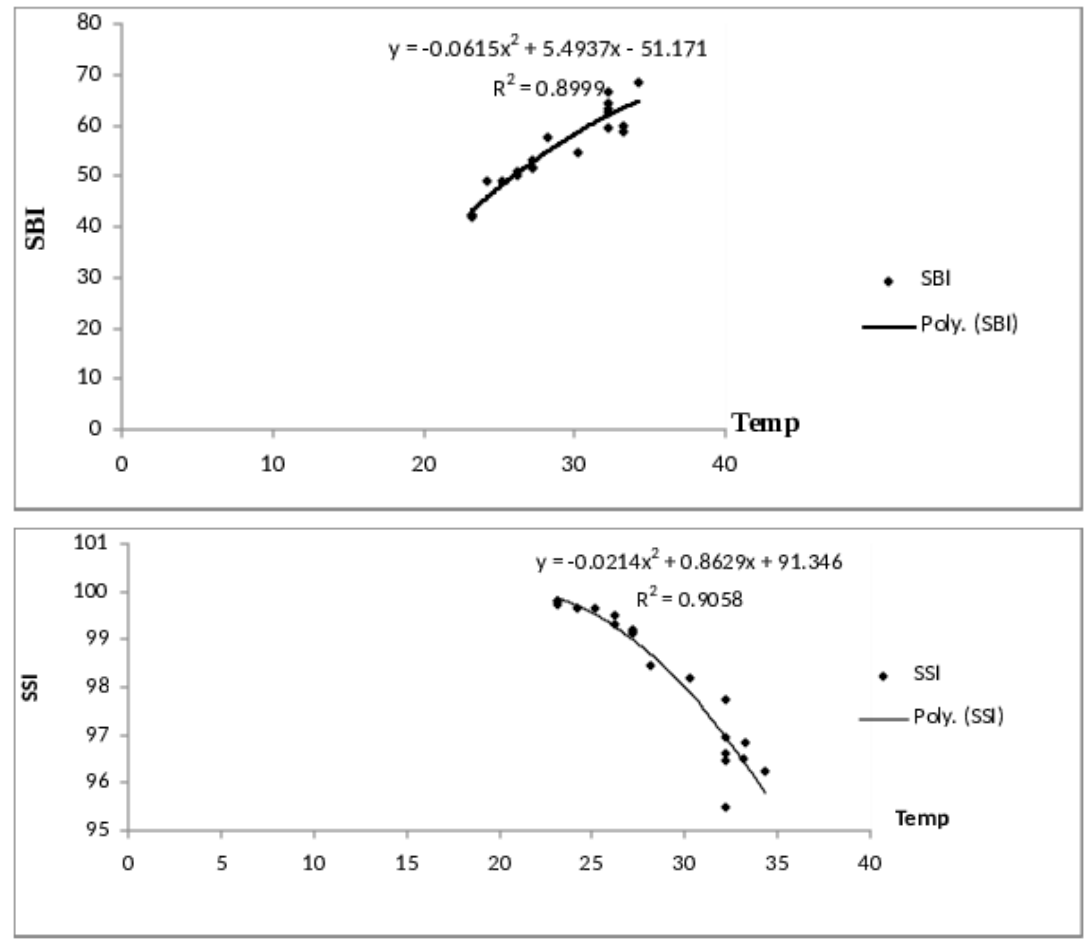

Figure 10: Bare soil and temperature (upper), forest shadow and temperature (lower) relationships in 2016.

\subsection{Result validation}

\section{Land Surface Temperature Validation through Near-Surface Air Temperature}

This method used the mean temperatures from three ground stations within the study area and the actual temperature in the given corresponding pixels on the same day of the satellite passing over the area for three representative points. For the Landsat OLI data, the mean temperature of retrieved LST are $307.35 \mathrm{~K}, 301.95 \mathrm{~K}$ and $306.15 \mathrm{~K}$ (or $34.2^{\circ} \mathrm{C}, 28.8^{\circ} \mathrm{C}$ and $33.0^{\circ} \mathrm{C}$ ) and the mean near-surface air temperatures are $307.65 \mathrm{~K}, 301.65 \mathrm{~K}$ and $306.77 \mathrm{~K}$ (or $34.5^{\circ} \mathrm{C}, 28.5^{\circ} \mathrm{C}$ and $\left.33.62^{\circ} \mathrm{C}\right)$. The LST retrieving error is about $-0.3^{\circ} \mathrm{C}, 0.3^{\circ} \mathrm{C}$, and $-0.62^{\circ} \mathrm{C}$ respectively. The air temperature and satellite data were acquired the same day $-2^{\text {nd }}$ of January, 2016. Table 6 shows the temperature values for the ground stations compared with the LST values of $2^{\text {nd }}$ of January, 2016. The spatial consistency of Landsat temperature results with an average error of about $\pm 0.21^{\circ} \mathrm{C}$ indicated that remote sensing data are comparable with the ground data in Akure metropolis.

\section{Conclusion}

For the past 32 years, Akure metropolitan area has undergone dramatic change in land surface characteristics. Landsat thermal band data were used to extract surface temperatures for 1984, 1992, 2000, 2003, 2014 and 2016. Through the retrieved temperature data, it was discovered that the distribution of surface temperature in the study area is mainly located in developed and bare surfaces. So it is reasonable to envisage the establishment of green 
Table 5: Ground-Pixel based Temperatures

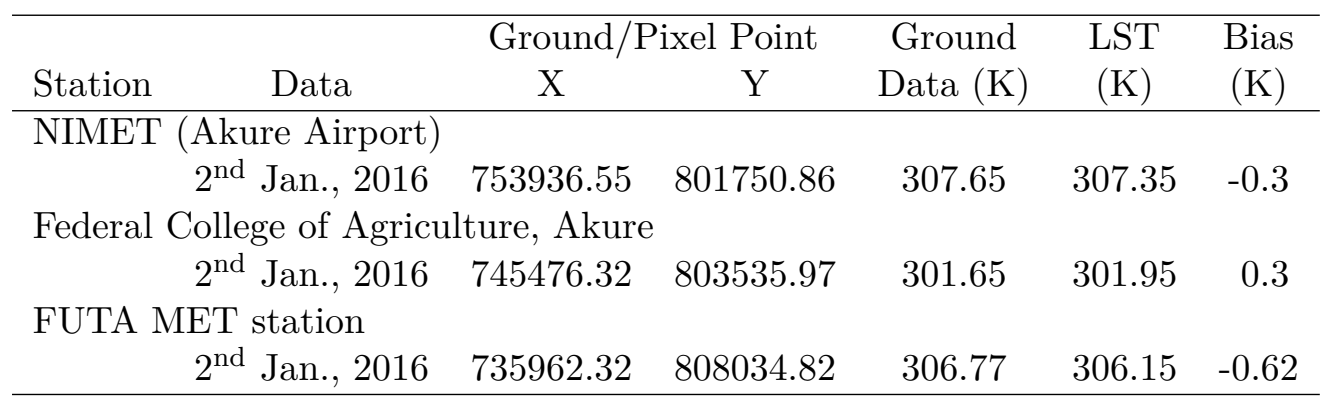

belt in the city in order to prevent the formation of a large-scale and very intensive urban heat island. This LST result could assist particularly the urban planners to understand urban climate as well as finding solution of managing urban environment. Data quality and accuracy assessment of results was conducted with available ground temperature information. Although the assessment revealed spatial consistency of Landsat temperature results in comparison with ground data, future study should utilize more ground data collection.

\section{References}

[1] Balogun Ifeoluwa Adebowale and Samakinwa Eric Kayode. "Geospatial Assessment of Urban Expansion and Land Surface Temperature in Akure, Nigeria." In: ICUC9 - 9th International Conference on Urban Climate jointly with 12th Symposium on the Urban Environment. 2015.

[2] Slady Akikel and Sailesh Samanta. Land Use/Land Cover and Forest Canopy Density Monitoring of Wafi-Golpu Project Area. Papua New Guinea, 2016.

[3] Ugur Avdan and Gordana Jovanovska. "Algorithm for Automated Mapping of Land Surface Temperature Using LANDSAT 8 Satellite Data". In: Journal of Sensors 2016 (2016), pp. 1-8. DOI: 10.1155/2016/1480307.

[4] Z Azizia, A Najafi, and H Sohrabia. "Forest Canopy Density Estimating, Using Satellite Images." In: 21st International Society for Photogrammetry and Remote Sensing (ISPRS) Congress, Beijing 37 (2008), pp. 1127-1130.

[5] James B Campbell. Introduction to Remote Sensing. 3rd Edition. 2005.

[6] Liqin Cao et al. Remote Sensing Image-Based Analysis of the Relationship Between Urban Heat Island and Vegetation Fraction. 2008.

[7] T N Carlson and D A Ripley. "On the relation between NDVI, fractional vegetation cover, and leaf area index". In: Remote Sensing of Environment 62 (1997), pp. 241-252.

[8] Y Chen, J Wang, and X Li. "A study on urban thermal field in summer based on satellite remote sensing". In: Remote Sensing for Land and Resources 4 (2002), pp. 554-598.

[9] M B Giannini et al. "Land Surface Temperature from Landsat 5 TM images: comparison of different methods using airborne thermal data measurements and comparison with MODIS remote sensing estimates." In: Agricultural and Forest Meteorology 129 (2015), pp. 151-173. 
[10] The Heat Island Group. Heat Island Effect (n.d.) Feb. 2005. URL: http://eetd/lbl/ gov/HeatIsland/.

[11] R P Kirtti, G Phanindra, and R K Mishrab. "Measuring Weather Impact on Crop Yield Using Aridity Index: Evidence from Odisha". In: Agricultural Economics Research Review 25.2 (2012), pp. 205-216.

[12] T Laosuwan and S Sangpradit. "Urban heat island monitoring and analysis by using integration of satellite data and knowledge based method". In: International Journal of Development and Sustainability 1.2 (2012), pp. 99-110.

[13] L Liu and Y Zhang. "Urban heat island analysis using the Landsat TM data and ASTER data: A Case study in Hong Kong". In: Remote Sensing 3 (2011), pp. 1535-1552.

[14] M Luck and J Wu 2002. "A gradient analysis of urban landscape pattern: A case study from the Phoenix metropolitan region Arizona, USA". In: Landscape Ecology 17.4 (2002), pp. 327-339.

[15] Aderoju M Olaide, Samakinwa E Kayode, and Ibrahim Dris. "An Assessment of Urban Heat Island in Akure Using Geospatial Techniques". In: Journal of Environmental Science, Toxicology and Food Technology 6.3 (2013), pp. 24-34. ISSN: 2319-2402. URL: www. Iosr journals. Org.

[16] A Rikimaru and S Miyatake. Development of Forest Canopy Density Mapping and Monitoring Model using Indices of Vegetation, Bare soil and Shadow. 1997.

[17] P Schneider et al. LST Validation Protocol. Tech. rep. ESA Contract Number: 19054/05/NL/FF. Norwegian Institute for Air Research and Earth Obswrvation Science, Space Research Centre, Department of Physics \& Astronomy, University of Leicester, 2012.

[18] J A Sobrino and N Raissouni. "Toward remote sensing methods for land cover dynamic monitoring. Application to Morocco". In: International Journal of Remote Sensing 21 (2002), pp. 353-366.

[19] National Bureau of Statistics: National Population commission of Nigeria. Annual Abstract of Statistics. 2010.

[20] J Voogt. "Urban Heat Island." Encyclopedia of Global Environmental Change 3". In: 1984, pp. 660-666.

[21] James A Voogt. Urban Heat Islands: Hotter Cities. 2004. URL: http://www . actionbioscience. org/environment/voogt.html.

[22] Q Weng. "A remote sensing-GIS evaluation of urban expansion and its impact on surface temperature in Zhujiang Delta, China". In: International Journal of Remote Sensing 22.10 (2001), pp. 1999-2014. DOI: 10.1080/713860788. 